\title{
Experimental Investigation of Wallboard Containing Phase Change Material: Data for Validation of Numerical Modeling
}

\author{
F. Kuznik ${ }^{\mathrm{a}, *}$ J. Virgone ${ }^{\mathrm{b}}$ \\ ${ }^{a}$ Thermal Sciences Center of Lyon \\ CNRS, UMR 5008, INSA de Lyon, Université Lyon 1 \\ Bt. Sadi Carnot, 9 rue de la Physique - 69621 Villeurbanne Cedex, France \\ ${ }^{\mathrm{b}}$ Université de Lyon, Université Lyon 1 \\ DGCB laboratory, URA 1652,ENTPE rue Maurice Audin \\ 69518 Vaulx-en-Velin Cedex, France
}

\begin{abstract}
In construction, the use of Phase Change Materials (PCM) allows the storage/release of energy from the solar radiation and/or internal loads. The application of such materials for lightweight construction (e.g. a wood house) makes it possible to improve thermal comfort in summer and reduce heating energy consumption in winter. The choice of a PCM depends deeply on the building structure, on the weather and on building use: numerical modeling is indispensable. In this paper, an experimental comparative study is described, using cubical test cells with and without PCM composite. A set of experimental data is detailed, concerning the air and wall temperatures. The results are compared with a numerical modeling and show that hysteresis must be taken into account to predict correctly the heat transfer.
\end{abstract}

Key words: experimental data, PCM composite, phase change material, 
wallboard, thermal energy storage, hysteresis.

\section{Introduction}

Nowadays, thermal energy storage systems are essential for reducing dependency on fossil fuels and then contributing to a more efficient environmentally benign energy use [1]. As demand in thermal comfort of buildings rises increasingly, the energy consumption is correspondingly increasing. For example, in France, the energy consumption of buildings has increased by $30 \%$ the last 30 years. Housing and tertiary buildings are responsible for the consumption of approximatively $46 \%$ of all energies and approximatively $19 \%$ of the total $\mathrm{CO}_{2}$ emissions [2].

Thermal energy storage can be accomplished either by using sensible heat storage or latent heat storage. Sensible heat storage has been used for centuries by builders to store/release passively thermal energy, but a much larger volume of material is required to store the same amount of energy in comparison to latent heat storage. The principle of the phase change material (PCM) use is simple. As the temperature increases, the material changes phase from solid to liquid. The reaction being endothermic, the PCM absorbs heat. Similarly, when the temperature decreases, the material changes phase from liquid to solid. The reaction being exothermic, the PCM desorbs heat.

The main disadvantage of light weight buildings concerning thermal comfort and energy consumption is their low thermal energy storage potential in walls.

\footnotetext{
* Corresponding author. Tel.: +33-472-438-461; Fax: +33-472-438-522

Email address: frederic.kuznik@insa-lyon.fr (F. Kuznik).
} 
Obviously, they tend to large temperature fluctuations due to external cooling or heating loads. Using PCM material in such building walls can decrease the temperature fluctuations, particularly in case of solar radiations loads. It is then a potential method for reducing energy consumption in passively designed buildings. This tendency is confirmed by numerous papers. For a review, see in $[3]$.

When selecting a PCM, the average room temperature should be close to the melting/freezing range of the material. Moreover, the day fluctuations should allow the material phase change. Then many factors influence the choice of the PCM: weather, building structure and thermophysical properties,... Numerical simulation must then be used to achieve the practical application of this technology. In order to validate a PCM numerical model, experimental data are essential.

The table 1 summarizes, not exhaustively, some experimental studies concerning measurements held in a room with walls containing PCM wallboards. Most of these experiments were carried out in outdoor conditions. Even if these conditions are more realistic, all of the weather parameters are not known (or measured). These studies cannot then be used to validate a numerical model requiring all of the experimental conditions. Concerning the number of the test cells, few studies use two identical cells with and without PCM. From a numerical point of view, having experiments with and without PCM is useful to verify the basic modeling.

The part 2 of this article presents the two identical test cells called MICROBAT and the PCM tested. Two kinds of external temperature evolutions are tested: heating and cooling steps with various slopes and sinusoidal temper- 
ature evolution with $24 h$ period. The part 3 deals with the results of the temperature steps. The sinusoidal external temperature results are presented in the next part of the paper. The part 5 is dedicated to the numerical modeling of the experiments: the main assumptions of the model are presented, then the simulations are compared with experimental data and finally, the numerical modeling is discussed.

\section{Description of the test cells MICROBAT}

Two identical test cells are used to investigate the effects of the PCM wallboards. The design of the test cells is presented part 2.1. The phase change material tested is described part 2.2. The part 2.3 deals with the measurement systems and the probes, the experimental protocol is given part 2.4.

\subsection{Design of the cells}

Two identical test cells are used in the study. Each test cell is a cubical enclosure with an internal dimension of $0.50 \mathrm{~m}$ (figure 1). The skeleton of MICROBAT is made of polish aluminium and is not painted in order to minimize the shortwave radiative heat transfer with the surroundings.

The front face of MICROBAT is an aluminium plate of $2 m m$ thickness. This face is called the active face because of its low thermal inertia and low thermal resistance. It enhances the heat transfer between the exterior and the interior of MICROBAT. The other faces of the test cells are of two types:

$\Longrightarrow$ the normal face (figure 2), mainly composed of insulating material in order 
to have a low thermal inertia wall,

$\Longrightarrow$ the PCM face (figure 2), which contains $5 \mathrm{~mm}$ of a phase change material wallboard.

The witness box has five normal faces whereas the PCM box contains three PCM faces which are the back face, the right face and the left face.

The thermophysical properties of the materials are given in table 2. All of the internal faces are painted in black, the absorption coefficient in short-wave being measured at about 0.96 .

\subsection{Phase change material tested}

The product tested, ENERGAIN ${ }^{\circledR}$ has been achieved by the Dupont de Nemours Society and is constituted of $60 \%$ of microencapsulated paraffin within a copolymer. The final form of the composite PCM material (see figure 3 ) is a flexible sheet of $5 \mathrm{~mm}$ thickness which density is about $900 \mathrm{~kg} \cdot \mathrm{m}^{-3}$. The thickness of the PCM is the result of an optimization study that can be found in [12].

The composite PCM heat capacity has been measured using a differential scanning calorimeter; the heating and cooling rate being $0.05 \mathrm{Kmn}^{-1}$. This rate corresponds to $3^{\circ} \mathrm{C} / h$ which is an average heating rate in a light weight building during summer season and when solar gains are maximum. The thermal analysis is given for the range $\left[1^{\circ} \mathrm{C} ; 34^{\circ} \mathrm{C}\right]$. Two curves are presented: the freezing curve (cooling from $34^{\circ} \mathrm{C}$ to $1^{\circ} \mathrm{C}$ ) and the melting curve (heating from $1^{\circ} \mathrm{C}$ to $34^{\circ} \mathrm{C}$ ). Figure 4 shows the measured values of heat capacity. The nearly Gaussian curves correspond to an intermediate phase change for 
the material [13]. Paraffin PCMs display a wider melting range compared to inorganic PCMs (narrow phase change zone). The physical properties of the composite PCM are:

$\star$ peak melting temperature $=22.3^{\circ} \mathrm{C}$,

$\star$ peak freezing temperature $=17.8^{\circ} \mathrm{C}$,

$\star$ specific heat at the melting peak $=13.4 \mathrm{Jg}^{-1} \mathrm{~K}^{-1}$,

$\star$ specific heat at the freezing peak $=12.9 \mathrm{Jg}^{-1} \mathrm{~K}^{-1}$,

$\star$ solid specific heat $=2.4 \mathrm{Jg}^{-1} \mathrm{~K}^{-1}$.

The latent heats of freezing and melting are respectively $71.0 \mathrm{~J} / \mathrm{g}$ and $72.4 \mathrm{~J} / \mathrm{g}$.

The difference between the melting temperature and the freezing temperature characterizes the hysteresis of the material, i.e. the fact that the mixture is not an eutectic. The figure 5 shows the measured enthalpy of the composite PCM function of temperature. This curve is typical of the hysteresis loop. Concerning the numerical modeling of this phenomenon, there is a memory effect and then the order of previous events influences the order of subsequent events.

The thermal conductivity has been measured using guarded hot-plate apparatus [11]. The thermal conductivity is $0.22 W \cdot \mathrm{m}^{-1} \cdot K^{-1}$ in liquid phase $\left(\theta>25^{\circ} \mathrm{C}\right)$ and decreases to about $0.18 \mathrm{~W} \cdot \mathrm{m}^{-1} \cdot \mathrm{K}^{-1}$ in solid phase $\left(\theta<5^{\circ} \mathrm{C}\right)$.

\subsection{Instrumentation and measurements}

All of the temperatures are measured using Pt100 sensors with a calculated resolution of $\pm 0.25^{\circ} \mathrm{C}$. The exterior temperature is measured. In each test cell 
the set of probes is:

- the internal face temperature, measured at the center of the face, with a probe included in the wall surface,

- the active face external temperature, measured at the center of the face,

- the air temperature, measured at the center of the cubical air volume.

A total of 17 probes is used in the experiment. The acquisition is done by the means of a multiplexer-multimeter connected to a personal computer. The time step chosen between two series of measurement is $2 m n$ and the duration of each test is about three days.

\subsection{Experimental protocol}

The two MICROBAT test cells are placed into a climatic chamber. The climatic chamber temperature can vary between $-10^{\circ} \mathrm{C}$ and $40^{\circ} \mathrm{C}$ as a function of time. The active face allows to impose the same external temperature for each test cell. The air in the climatic chamber is mixed in order to avoid temperature gradients; the mean air velocity in this chamber is about $0.5 \mathrm{~m} / \mathrm{s}$.

Two types of external temperature evolutions are investigated:

- a temperature step, heating and cooling,

- a sinusoidal temperature evolution.

Concerning the heating/cooling temperature step, three cases are tested depending on the slope (SL) i.e. the time needed to reach the constant temperature value: 1 hour, 2 hours or 3 hours. The figure 6 shows the temperature step parameters. A time delay of 20hours is needed for the two cells to reach the 
same stationary thermal state.

The sinusoidal temperature evolution is 24 hours periodic and varies between $15^{\circ} \mathrm{C}$ and $30^{\circ} \mathrm{C}$ (figure 6 ).

\section{Temperature step}

The first experiment concerns the temperature steps (heating and cooling) and the present part deals with the results of the cases tested. The part 3.1 deals with general considerations concerning the measurements. The air temperatures is analyzed part 3.2 and the internal face temperature part 3.3.

\subsection{General considerations}

The box without PCM is strongly insulated but with a relatively low thermal inertia. The figure 7 shows the measured temperatures for the internal faces and air in the test cell without PCM for the case $S L=1$ hour. Except for the active face, the other faces temperatures and the air temperature are nearly identical. The temperature gradient in the box does not affect the heat transfer, and particularly the convection heat transfer. This conclusion is valid for all the cases tested and then only air temperature is presented in the following paragraphs of the article. 


\subsection{Air temperature analysis}

\subsubsection{Heating step}

The air temperature measured for the three kinds of heating steps and for the two test cells is presented in figure 8. The air temperature for the box without $\mathrm{PCM}$ is close to the exterior temperature with a little time lag due to the low thermal inertia of the box. The storage effect of PCM affects much the air temperature.

The air temperature evolution of the witness box is nearly exponential. For the box with PCM, the temperature evolution is composed of three stages:

(1) for $\theta(t) \lesssim 21^{\circ} \mathrm{C}$, the air temperature is increasing linearly with a slope $S L 1$ (definition of $S L_{h}$ is given figure 6),

(2) for $21^{\circ} \mathrm{C} \lesssim \theta(t) \lesssim 30^{\circ} \mathrm{C}$, the air temperature is increasing with a slope lower than $S L_{h}$ due to the phase change,

(3) for $\theta(t) \approx 30^{\circ} \mathrm{C}$, the temperature has reached a steady state.

In order to evaluate the time lag due to the PCM, the $\tau$ value is introduced and defined as:

$$
\theta(2 \tau)=\theta(0)+\left(1-e^{-2}\right)(\theta(\infty)-\theta(0))
$$

where $\theta(t)$ is the air temperature at time $t$. For an exponential temperature evolution, $\tau$ is the time needed to reach $63.2 \%$ of the infinite temperature value.

The table 3 summarizes the $\tau$ values for the heating step cases. The $\tau$ ratio between the case with PCM and without PCM varies between 3.9 and 2.4: 
the more the slope of the external temperature step is important, the more the ratio is important. Consequently, the more the heating excitation is rapid, the more the PCM wallboard is efficient for slowing down the temperature increase.

\subsubsection{Cooling step}

The air temperature measured for the three kinds of cooling steps and for the two test cells is presented in figure 9. The conclusions from this figure are quite similar to those of the heating step i.e.: the air temperature for the box without PCM is close to the exterior temperature with a little time lag due to the low thermal inertia of the box and the storage effect of PCM affects much the air temperature.

The air temperature evolution of the witness box is nearly exponential. For the box with PCM, the temperature evolution is composed of three stages:

(1) for $\theta(t) \gtrsim 19^{\circ} \mathrm{C}$, the air temperature is decreasing linearly with a slope $S L_{c}$

(2) for $15^{\circ} \mathrm{C} \lesssim \theta(t) \lesssim 19^{\circ} \mathrm{C}$, the air temperature is decreasing with a slope lower than $S L_{c}$ due to the phase change,

(3) for $\theta(t) \approx 15^{\circ} \mathrm{C}$, the temperature has reached a steady state.

The main difference between the heating and the cooling is the flat part of the curve around $19^{\circ} \mathrm{C}$ appearing only for the cooling step cases. This flat part of the curve lasts about $1 h$. The PCM composite is composed of microencapsulated paraffin spheres included in a copolymer matrix. During the solidification process, the solid paraffin is evenly formed through the sphere, starting from 
the outer surface and moving inward. As the solidification proceeds, the melt volume decreases with a simultaneous decrease in the magnitude of natural convection within the melt and the process is therefore much longer [14].

The table 3 summarizes the $\tau$ values for the cooling step cases. The $\tau$ ratio between the case with PCM and without PCM varies between 5.2 and 3.0: the more the slope of the external temperature step is important, the more the ratio is important. Then, the more the cooling excitation is rapid, the more the PCM wallboard is efficient for slowing down the temperature decrease.

\subsection{Test cell with PCM: temperature evolution}

The phase change material included in the wallboards stores/releases energy transferred from the air volume mainly by convection. Then, the wall surfaces temperatures are an important feature in the phase change phenomenon. The figures 10 and 11 present the internal faces temperature, for the cell with PCM, and for the heating and cooling steps.

For all the cases tested, the three PCM walls have the same surface temperature. Similarly to the air temperature, the PCM wall temperature curves have a break of slope of about $21^{\circ} \mathrm{C}$ for the heating cases and $19^{\circ} \mathrm{C}$ for the cooling cases. For all of the cases tested, the temperature difference between the six faces of the cell never exceeds $5^{\circ} \mathrm{C}$. 


\subsection{Discussion}

The response of MICROBAT to an external temperature step is interesting to characterize the time lag due to the PCM. Of course, the presence of PCM allows to delay the box air temperature increase or decrease (as long as the temperature varies within the phase change range).

The analysis of the time lag defined paragraph 3.2.1 shows that the more the thermal excitation is rapid, the more the PCM is efficient. In buildings, rapid thermal excitation can be solar spot or internal load.

For the PCM used in wallboards, hysteresis exists and has clearly been exhibited in paragraph 2.2. This phenomenon has been few studied in literature and never been taken into account in numerical modeling as well as in experimental analysis. In the present study, an optimal use of the PCM requires a wall temperature above $22.3^{\circ} \mathrm{C}$ for energy storage process, and a wall temperature below $17.8^{\circ} \mathrm{C}$ for energy release process. From an engineering point of view, this phenomenon must be taken into account!

\section{External sinusoidal temperature evolution}

The response of the MICROBAT to an external temperature step allows to characterize the time lag due to PCM wallboards. In order to characterize the phase difference and the decrement factor due to PCM, an external sinusoidal temperature evolution is used, case which is closer to the real building configuration.

The figure 12 shows the air temperature curves for the two cells. The phase 
difference $\zeta$ is defined as the time difference between outdoor temperature maximum and indoor temperature maximum. For the cell with PCM, the phase difference $\zeta=138 \mathrm{~min}$ while this value is about $38 \mathrm{~min}$ without PCM. The decrement factor $f$ is defined as the ratio between indoor temperature amplitude and outdoor temperature amplitude. For the cell with PCM, the decrement factor $f=0.74$ while this value is about 0.89 without PCM.

The figure 13 presents the wall surface temperatures for the PCM box. For the walls with PCM, the temperature curve has two breaks of slope: one at about $19^{\circ} \mathrm{C}$ and one at about $22^{\circ} \mathrm{C}$. This feature is a characteristic of the hysteresis phenomenon of the PCM.

\section{$5 \quad$ Numerical modeling}

In the previous section, experimental data are described so that in the present section numerical modeling can be held. The paragraph 5.1 is dedicated to a presentation of the numerical modeling. Then, the numerical results are presented in paragraph 5.2. The paragraph 5.3 is a discussion concerning the numerical modeling.

\subsection{Presentation of the numerical modeling}

The first modeling step consists in decomposing the test cell (or the building) in elementary objects: air zones, walls,... The air zones are connected via walls. Each elementary object has homogeneous physical values: one surface temperature per wall, one temperature per air zone,...The problem treated in this article is composed of two air zones (inside and outside the test cell) and 
6 walls.

The temperature evolution in the test cell is calculated using the energy balance of the air volume.

For each wall, the conduction heat transfer is supposed to be unidirectional. The phase change is modeled using the equivalent heat capacity method: the exact heat capacity curve is approximated using splines. In order to solve numerically the problem, a finite-difference method is used: the continuous information contained in the exact solution of the differential equation are replaced by discrete temperature values. More information about such numerical scheme can be found in $[6]$.

Only the longwave radiation exchanges are considered in the present modeling. The external exchanges occur between the external surface of the walls and the climatic chamber walls. The internal exchanges occur between the internal surfaces of the walls. All the longwave radiation exchanges are fully calculated, using the form factor of the various surfaces.

All of the temporal problem equations are discretized using an implicit scheme. The time selected chose for the simulation is $60 \mathrm{~s}$. For the conduction problem, the spatial discretization results in 10 PCM nodes and 20 insulating material nodes. All the simulation parameters are optimized from a solution accuracy point of view. The software MATLAB is used for all the simulations. 


\subsection{Numerical results}

In this paragraph, the experimental data are compared with the numerical results obtained from our modeling. For the sake of brevity, only the results concerning the air temperature are presented in this paper.

The figure 14 shows the comparisons between experiments and modeling for the heating step. The modelings $(a),(b)$ and $(c)$ use the equivalent specific heat obtained with the data of the figure 4 melting curve. For the three cases, the numerical data are in good agreement with experiment. The figure $(d)$ shows that the freezing specific heat curve is not adapted for the heating step modeling.

The figure 15 shows the comparisons between experiments and modeling for the cooling step. The modelings $(a),(b)$ and $(c)$ use the equivalent specific heat obtained with the data of the figure 4 freezing curve. For the three cases, the numerical data are in quite good agreement with experiment, excepted for the flat part of the curve around $19^{\circ} \mathrm{C}$. Due to the nature of the flat plate of the curve, this feature is not modeled. The figure $(d)$ shows that the cooling specific heat curve is not adapted for the cooling step modeling.

The figure 16 shows the comparisons between experiments and modeling for the sinusoidal temperature evolution. From a modeling point of view, this type of evolution is complicated because it is composed of cooling and heating periods. Neither the freezing curve, nor the melting curve allows to predict the correct air temperature evolution. 


\subsection{Discussion concerning the numerical modeling}

The main problem of the PCM modeling is the way to introduce the phase change. In this paper, the equivalent specific heat has been tested. Unfortunately, the paraffin used is not an eutectic mixture, so hysteresis occurs during the phase change. When simulating heating step or cooling step separately, the numerical data are in good agreement with experiments only if the corresponding specific heat curve is used, e.g. melting curve and cooling curve.

For a sinusoidal temperature evolution, neither the melting curve nor the freezing curve allows to predict correctly the temperature evolution. The hysteresis phenomenon must the be taken into account correctly in order to predict the PCM composite thermal behavior.

\section{Conclusions and outlook}

The objective of this article is first, providing reliable experimental data that can be used for the validation of numerical modeling and then, studying some features related to the use of phase change material wallboard. A double test cell, MICROBAT, is used to measure the temperatures and characterize the phase change effects. The external temperature is the thermal excitation; a heating/cooling step and a sinusoidal evolution are tested.

The effects of PCM wallboard are to cause time lag between indoor and outdoor temperature evolutions and to reduce the external temperature amplitude in the cell. A comparison between the cases with and without PCM shows that the more the thermal excitation is rapid, the more the PCM is efficient. 
This enables the use of the phase change material for solar spot in building rooms.

The experimental data are then compared with numerical simulation. The heating steps and cooling steps are correctly predicted by modeling when the corresponding specific heat curve is used. For a sinusoidal temperature evolution, neither the melting curve nor the freezing curve allows to predict correctly the temperature evolution.

The effect of hysteresis phenomenon has been clearly exhibited with the experimental data: the melting process arises at a temperature higher than for the solidification process. The numerical modeling shows that the hysteresis phenomenon must be taken into account correctly in order to predict the PCM composite thermal behavior. Further investigations are needed to have a better numerical description of this special phase change feature.

\section{Acknowledgments}

The authors thank Hébert Sallé from the Centre Scientifique et Technique du Bâtiment (CSTB) for the DSC analysis.

\section{References}

[1] Dincer I., Rosen M.A. Thermal Energy Storage - Systems and Applications. Jhon Wiley and Sons (2002).

[2] French Ministry of Ecology and Sustainable Developpment. Climate Plan 2004: let's act together to challenge of climate change. Report; 87p. (2004) 
[3] Tyagi V.V., Buddhi D. PCM Thermal Storage in Buildings: A State of Art. Renewable and Sustainable Energy Reviews; 11: 1146-1166 (2007).

[4] Athienitis A.K., Liu C., Hawes D., Banu D., Feldman D. Investiagtion of the Thermal Performance of a Passive Solar Test Room with Wall latent Heat Storage. Building and Environment; 32: 405-410 (1997).

[5] Ahmad M., Bontemps A., Sallee H., Quenard D. Thermal Testing and Numerical Simulation of a Prototype Cell using Light Wallboards coupling Vacuum Isolation Panels and Phase Change Material. Energy and Buildings; 38: 673-681 (2006).

[6] Kuznik F., Virgone J., Roux J.J. Energetic Efficiency of Room Wall Containing PCM Wallboard: A Full-Scale Experimental Investigation. Energy and Buildings; 40: $148-156(2008)$.

[7] Shilei L.V., Neng Z., Guohui F. Impact of phase change room on indoor thermal environment in winter. Energy and Buildings; 38: 18-24 (2006).

[8] Voelker C., Kornadt O., Ostry M. Temperature reduction due to the application of phase change materials. Energy and Buildings; 40: 937-944 (2008).

[9] Cabeza L.F., Castellon C., Nogues M., Medrano M., Leppers R., Zubillaga O. Use of microencapsulated PCM in concrete walls for energy savings. Energy and Buildings; 39: 113-119 (2007).

[10] Zhang Y.P., Lin K.P., Yang R., Di H.F., Jiang Y. Preparation, thermal performance and application of shape-stabilized PCM in energy efficient buildings. Energy and Buildings; 38: 1262-1269 (2006).

[11] ASTM. Standard Test Method for Steady-State Heat Flux Measurements and Thermal Transmission Properties by Means of the Guarded-Hot-Plate Apparatus. Norm C177 (2004).

[12] Kuznik F., VirgoneJ. , Noel J. Optimization of a phase change material wallboard for building use. Applied Thermal Engineering; 28: 1291-1298 (2008). 
[13] Darkwa K., O'Callaghan P.W. Simulation of Phase Change Drywalls in a Passive Solar Building. Applied Thermal Engineering; 26: 853-858 (2006).

[14] Ettouney H., El-Dessouky H., Al-Ali A. Heat transfer during phase change of paraffin wax stored in spherical shells. Journal of solar energy engineering; 127: $357-365$ (2005). 


\section{List of Tables}

$1 \quad$ Experimental studies involving PCM wallboards. 22

$2 \quad$ Thermophysical properties of the materials. 23

3 Time lag values for for the various temperature steps - heating and cooling. 


\begin{tabular}{|c|c|c|c|}
\hline \multicolumn{4}{|c|}{ NOMENCLATURE } \\
\hline$f$ & decrement factor $[-]$ & $\theta$ & temperature $\left[{ }^{\circ} \mathrm{C}\right]$ \\
\hline$S L$ & temperature step slope $[$ hour $]$ & $\tau$ & time lag $[\min ]$ \\
\hline$t$ & time $[s]$ & & \\
\hline & & \multicolumn{2}{|c|}{ Subscripts } \\
\hline Greek Letters & & $c$ & cooling \\
\hline$\zeta$ & phase difference $[\mathrm{min}]$ & $h$ & heating \\
\hline
\end{tabular}




\begin{tabular}{ccccc}
\hline Ref. & PCM composite & Size & Number of cells & Conditions \\
\hline$[4]$ & butyl stearate / gypsum & $2.82 \mathrm{~m}, 2.22 \mathrm{~m}, 2.24 \mathrm{~m}$ & 1 & outdoor \\
\hline$[5]$ & polyethylene glycol / PVC panel & $0.9 \mathrm{~m}, 0.9 \mathrm{~m}, 0.9 \mathrm{~m}$ & 2 & outdoor \\
\hline$[6]$ & paraffin / polymer & $3.10 \mathrm{~m}, 3.10 \mathrm{~m}, 2.50 \mathrm{~m}$ & 1 & laboratory \\
\hline$[7]$ & capriclauric acids / gypsum & $5.00 \mathrm{~m}, 3.30 \mathrm{~m}, 2.80 \mathrm{~m}$ & 1 & outdoor \\
\hline$[8]$ & paraffin / plaster & $4.43 \mathrm{~m}, 2.95 \mathrm{~m}, 3.00 \mathrm{~m}$ & 2 & outdoor \\
\hline$[9]$ & paraffin / gypsum & $2.00 \mathrm{~m}, 2.00 \mathrm{~m}, 3.00 \mathrm{~m}$ & 2 & outdoor \\
\hline$[10]$ & paraffin / polyethylene & $3.00 \mathrm{~m}, 2.00 \mathrm{~m}, 2.00 \mathrm{~m}$ & 1 & outdoor \\
\hline
\end{tabular}

Table 1

Experimental studies involving PCM wallboards. 


\begin{tabular}{lccc}
\cline { 2 - 4 } & $\begin{array}{c}\text { density } \\
{\left[\mathrm{kg} / \mathrm{m}^{3}\right]}\end{array}$ & $\begin{array}{c}\text { specific heat } \\
{[\mathrm{J} / \mathrm{kgK}]}\end{array}$ & $\begin{array}{c}\text { thermal conductivity } \\
{[\mathrm{W} / \mathrm{mK}]}\end{array}$ \\
\hline aluminium & 2700 & 8800 & 230.00 \\
insulating material & 35 & 1210 & 0.04 \\
cardboard & 730 & 1110 & 0.27 \\
\hline
\end{tabular}

Table $\overline{2}$

Thermophysical properties of the materials. 


\begin{tabular}{cccc}
\hline$\tau[\mathrm{min}]$ & Box without PCM & Box with PCM & $\tau$ Ratio \\
\hline \hline Heating & & & \\
Step $1 h$ & $48 \mathrm{~min}$ & $188 \mathrm{~min}$ & 3.9 \\
Step $2 h$ & $70 \mathrm{~min}$ & $207 \mathrm{~min}$ & 3.0 \\
Step $3 h$ & $93 \mathrm{~min}$ & $221 \mathrm{~min}$ & 2.4 \\
\hline \hline Cooling & & & \\
Step $1 h$ & $48 \mathrm{~min}$ & $249 \mathrm{~min}$ & 5.2 \\
Step $2 h$ & $70 \mathrm{~min}$ & $262 \mathrm{~min}$ & 3.7 \\
Step $3 h$ & $93 \mathrm{~min}$ & $280 \mathrm{~min}$ & 3.0 \\
\hline
\end{tabular}

Time lag values for for the various temperature steps - heating and cooling. 


\section{List of Figures}

1 Schematic view of a test cell. 26

2 Composition of the test cell walls. 27

3 Duoont de Nemours material. 28

4 Experimental specific heat of the composite PCM. 29

$5 \quad$ Enthalpy of the composite PCM. 30

$6 \quad$ External temperature evolutions. 31

$7 \quad$ Temperatures for the box without PCM - case $S L=1$ hour. $\quad 32$

8 Temperatures for the boxes with and without PCM - external temperature increase.

9 Temperatures for the boxes with and without PCM - external temperature decrease.

10 Temperatures for the boxes with PCM - external temperature increase.

11 Temperatures for the boxes with PCM - external temperature decrease.

12 Temperatures for the boxes with and without PCM - external sinusoidal temperature evolution.

13 Temperatures for the boxes with PCM - external sinusoidal temperature evolution.

14 Comparison between experimental data and numerical modeling - Heating step. (a), (b) and (c) are modeling using the melting curve of figure 4 whereas (d) uses the freezing curve

15 Comparison between experimental data and numerical modeling - Cooling step. (a), (b) and (c) are modeling using the freezing curve of figure 4 whereas (d) uses the melting curve

16 Comparison between experimental data and numerical modeling - Sinusoidal temperature evolution. 


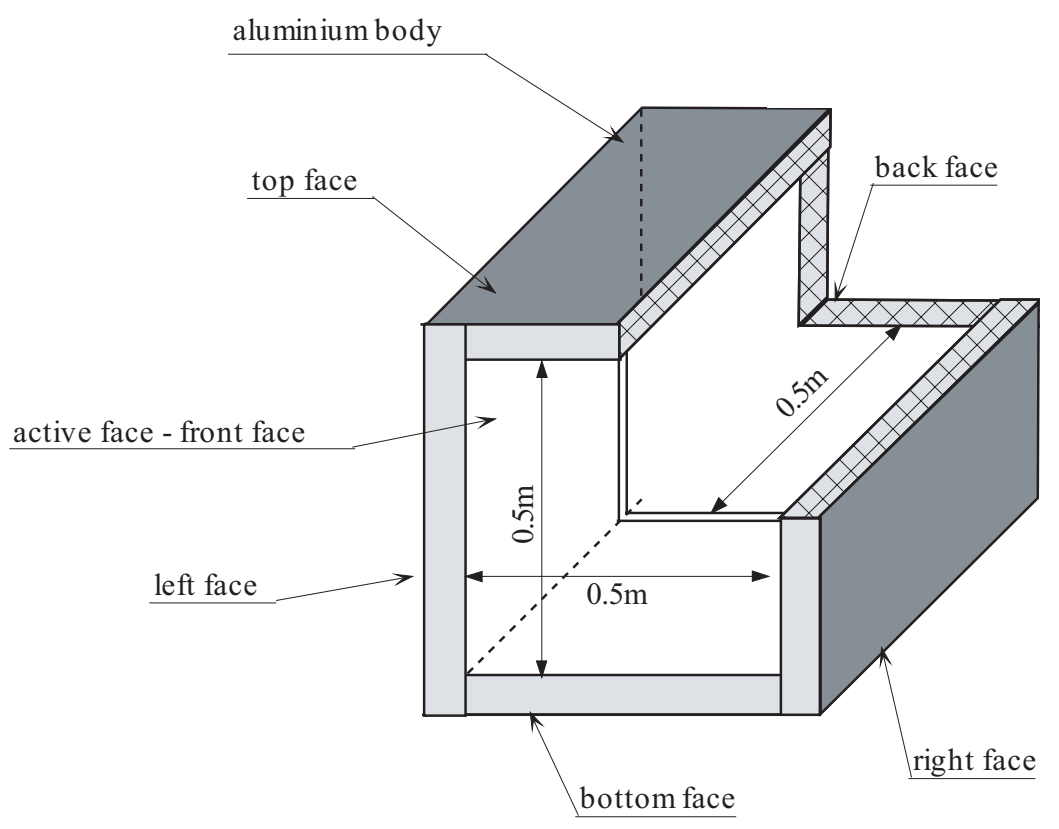

Fig. 1. Schematic view of a test cell. 

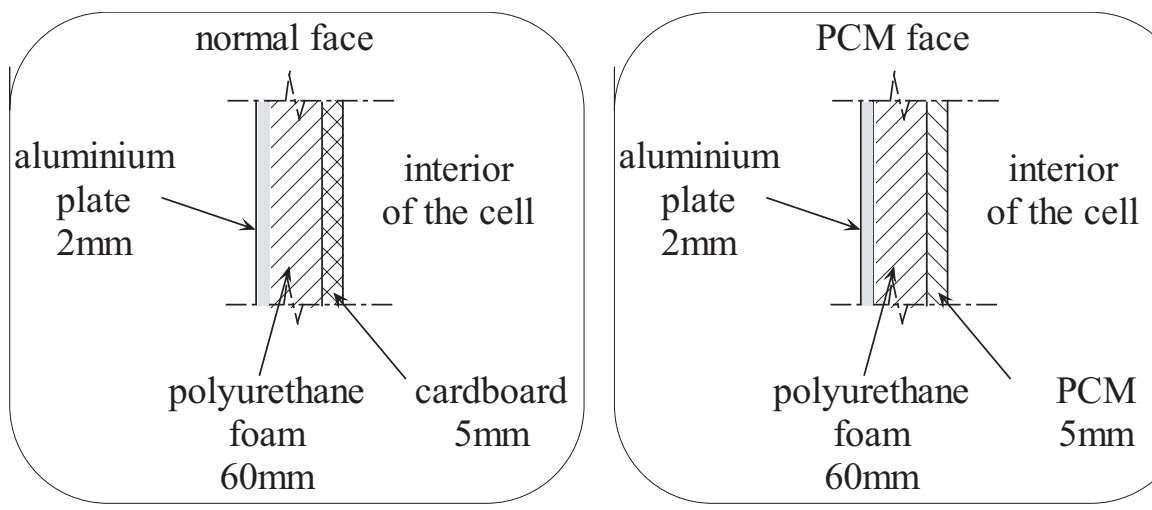

Fig. 2. Composition of the test cell walls. 


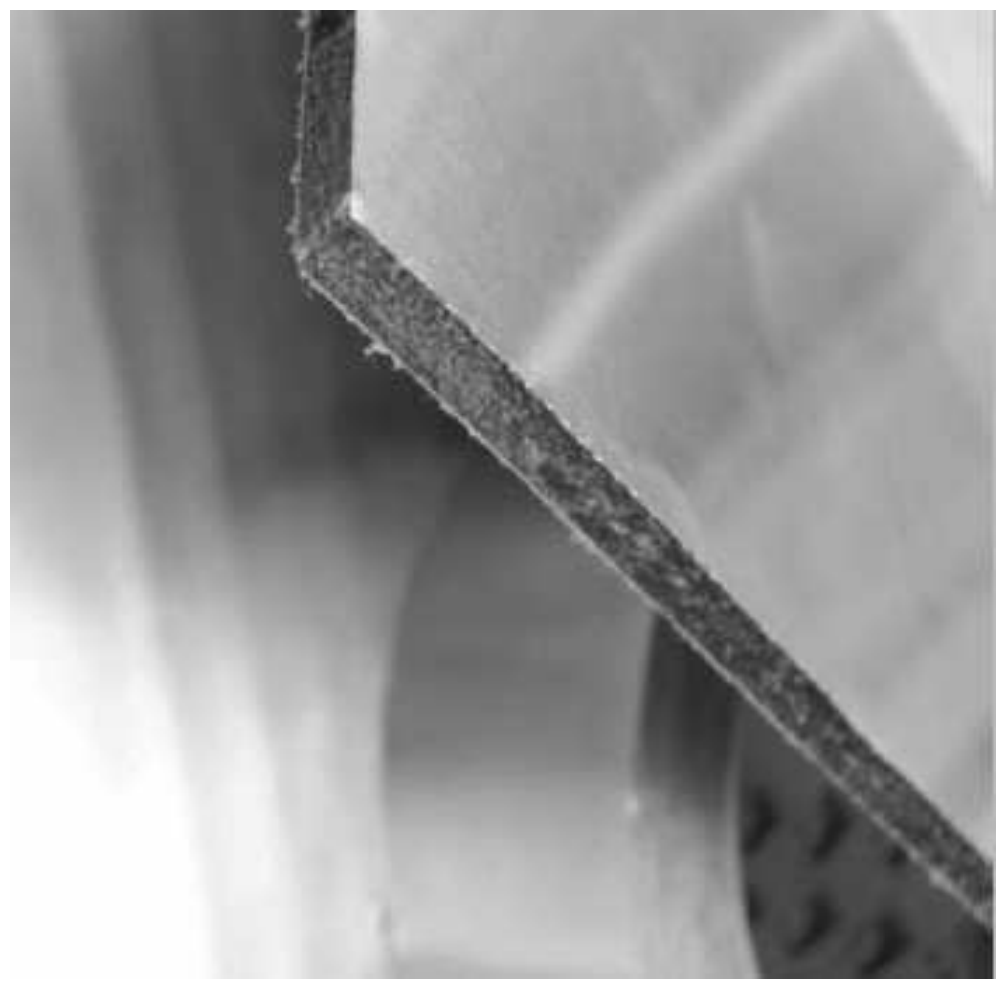

Fig. 3. Duoont de Nemours material. 


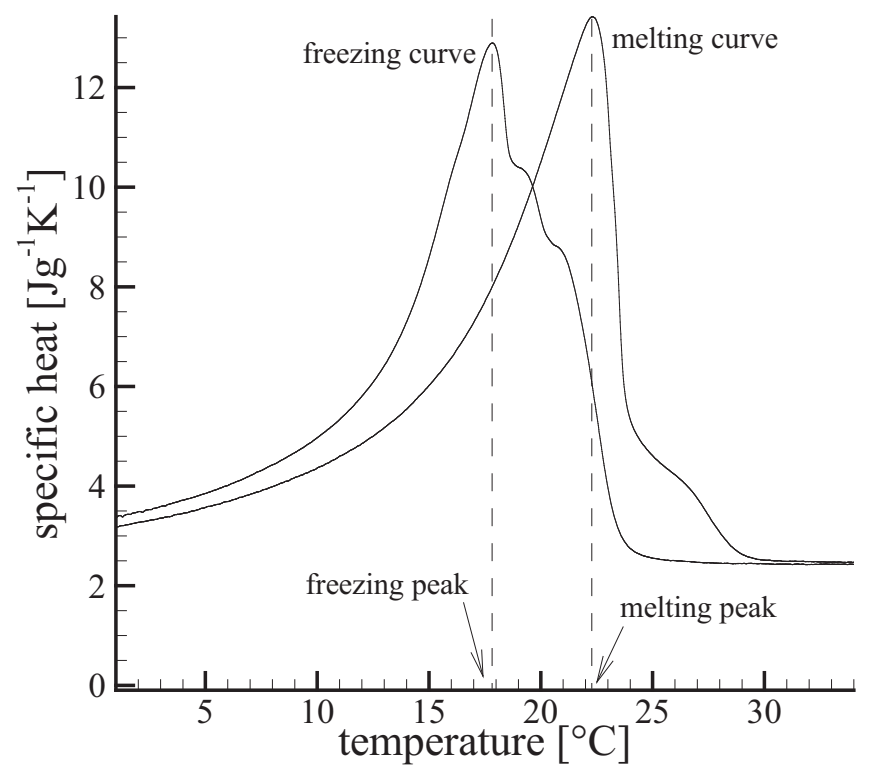

Fig. 4. Experimental specific heat of the composite PCM. 


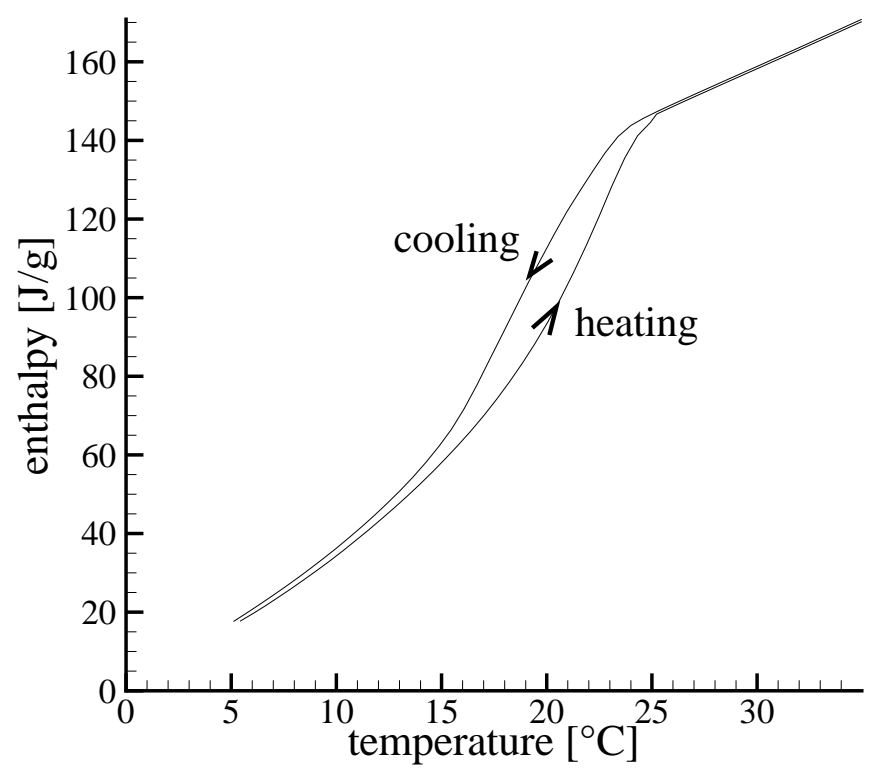

Fig. 5. Enthalpy of the composite PCM. 


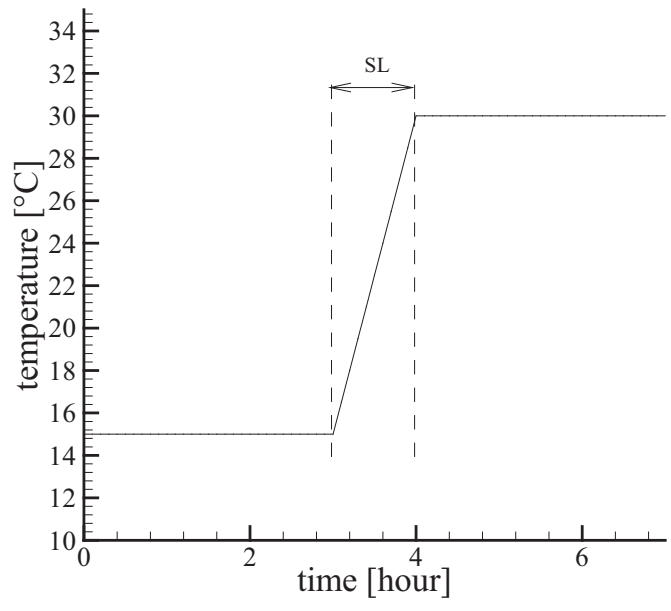

step curve

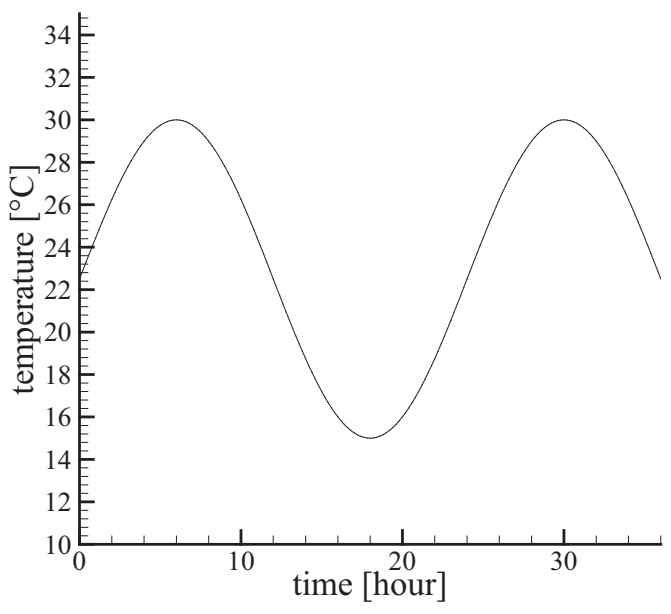

sine curve

Fig. 6. External temperature evolutions. 


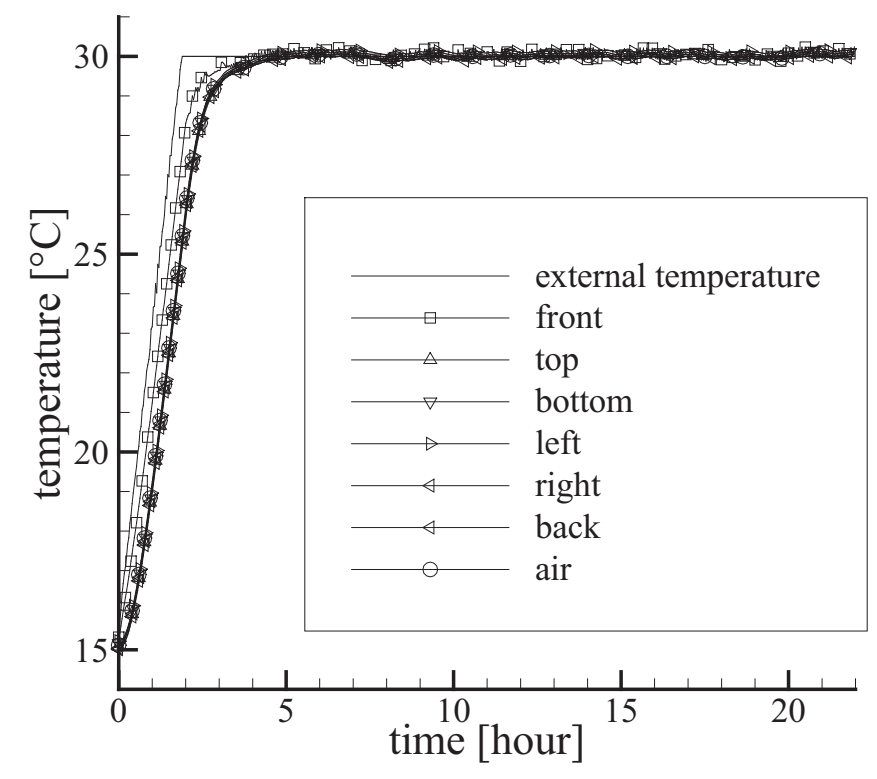

Fig. 7. Temperatures for the box without PCM - case $S L=1$ hour. 


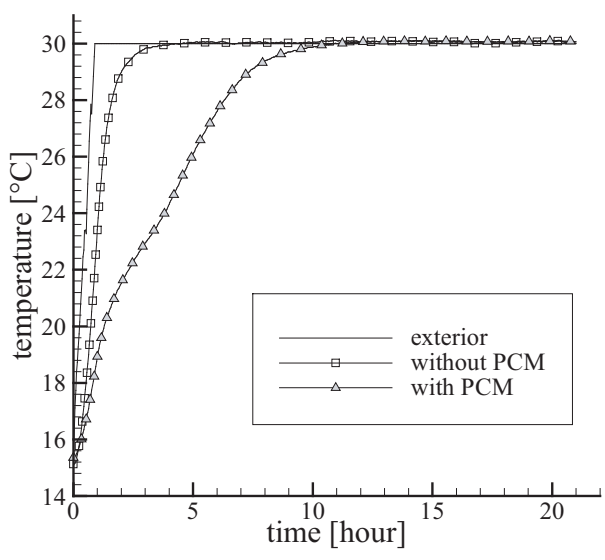

(a) $\mathrm{SL}=1$ hour

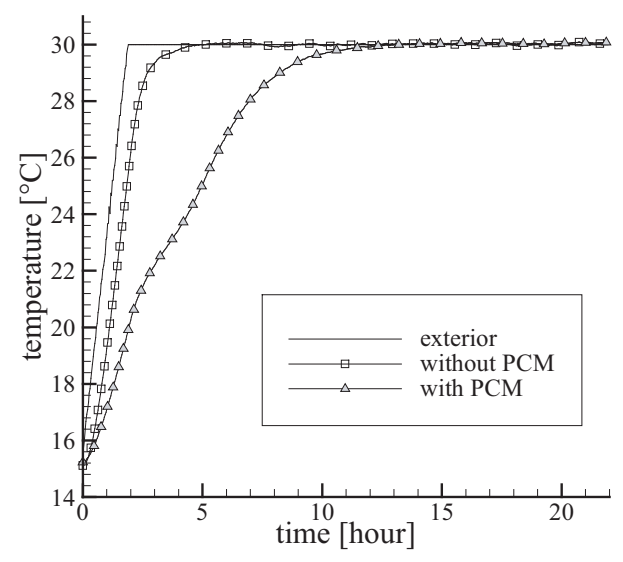

(b) $\mathrm{SL}=2$ hours

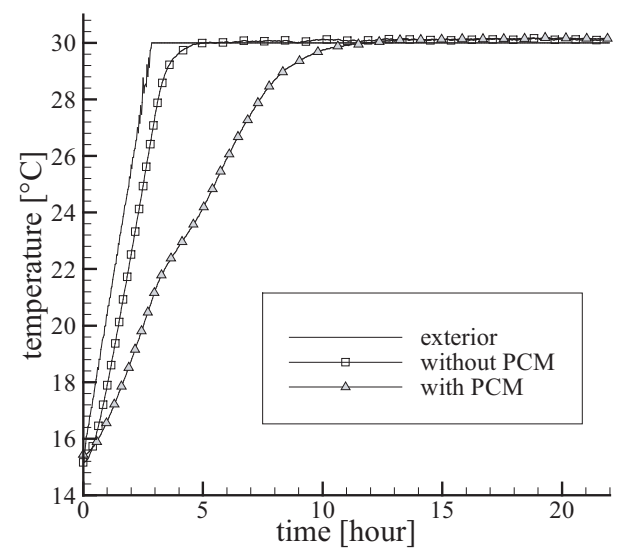

(c) $\mathrm{SL}=3$ hours

Fig. 8. Temperatures for the boxes with and without PCM - external temperature increase. 


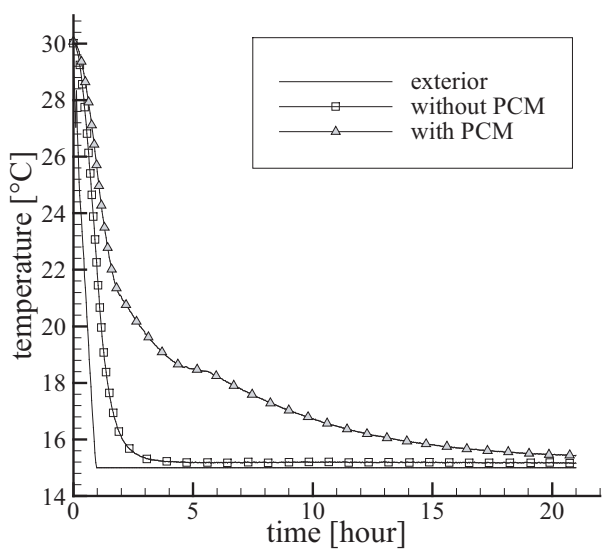

(a) $\mathrm{SL}=1$ hour

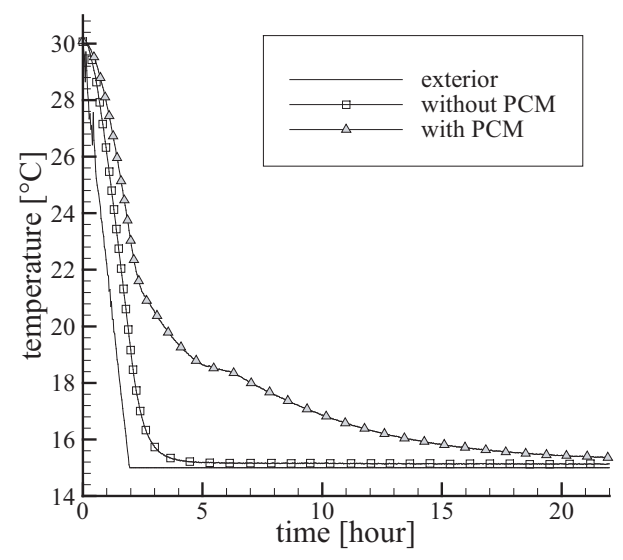

(b) $\mathrm{SL}=2$ hours

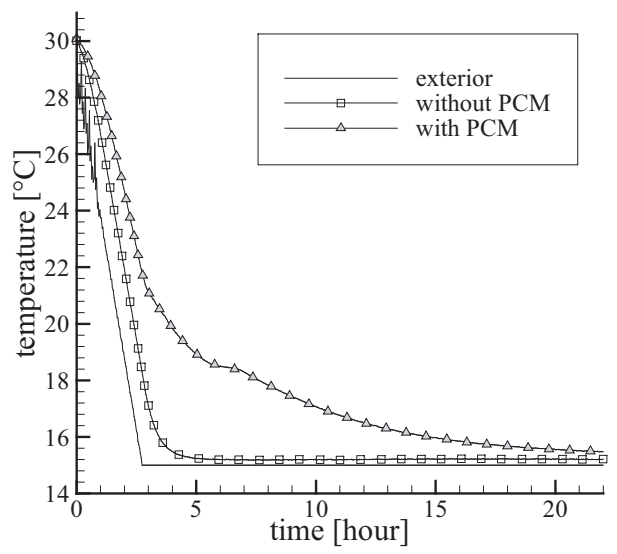

(c) $\mathrm{SL}=3$ hours

Fig. 9. Temperatures for the boxes with and without PCM - external temperature decrease. 


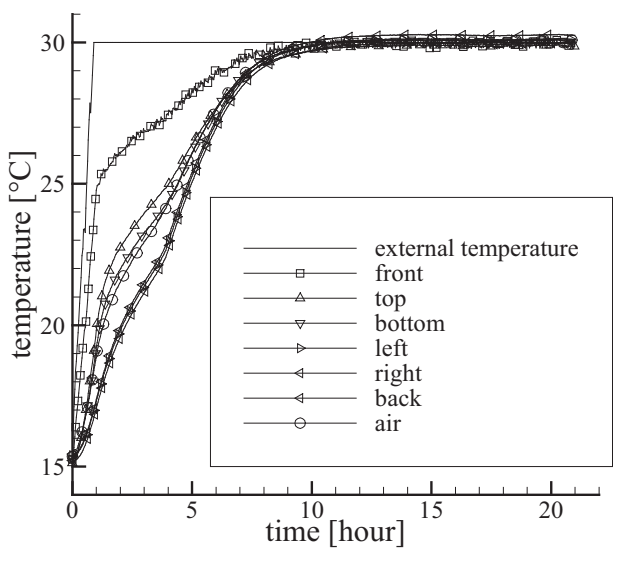

(a) $\mathrm{SL}=1$ hour

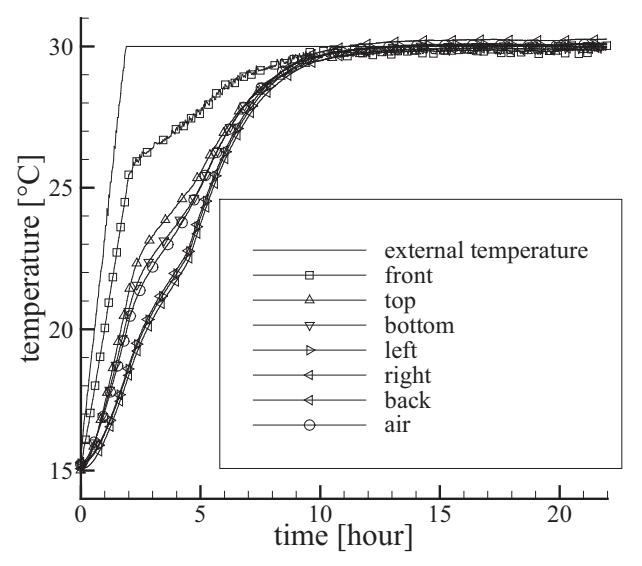

(b) $\mathrm{SL}=2$ hours

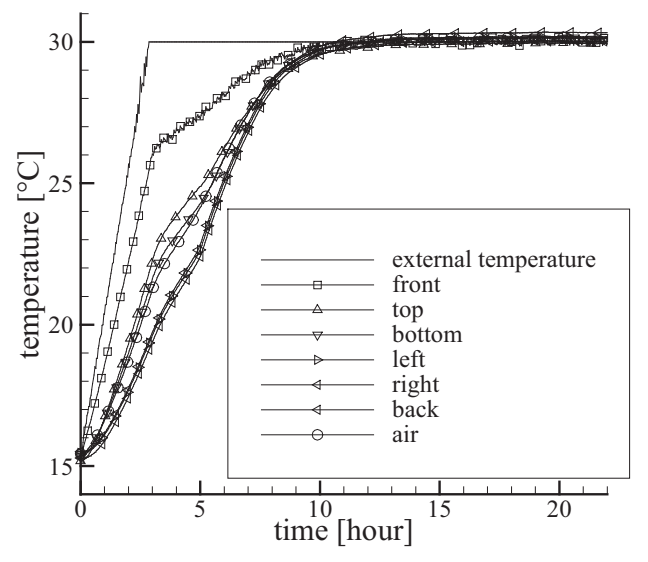

(c) $\mathrm{SL}=3$ hours

Fig. 10. Temperatures for the boxes with PCM - external temperature increase. 


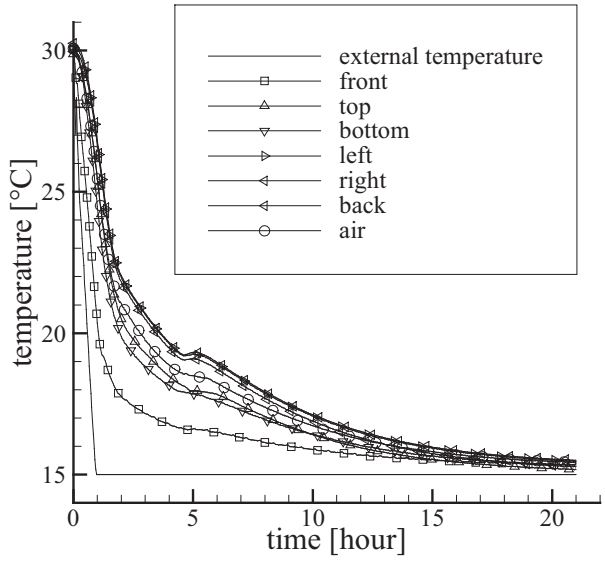

(a) $\mathrm{SL}=1$ hour

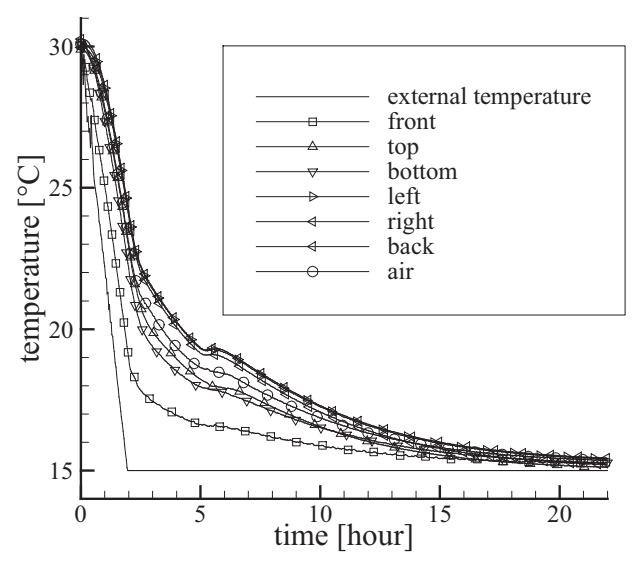

(b) $\mathrm{SL}=2$ hours

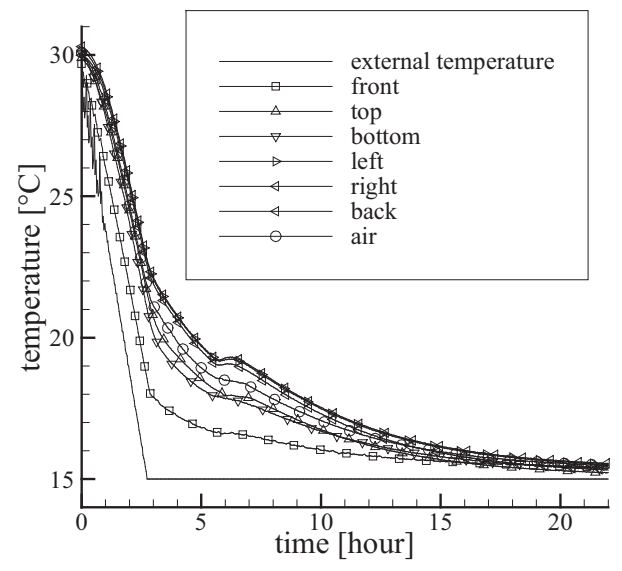

(c) $\mathrm{SL}=3$ hours

Fig. 11. Temperatures for the boxes with PCM - external temperature decrease. 


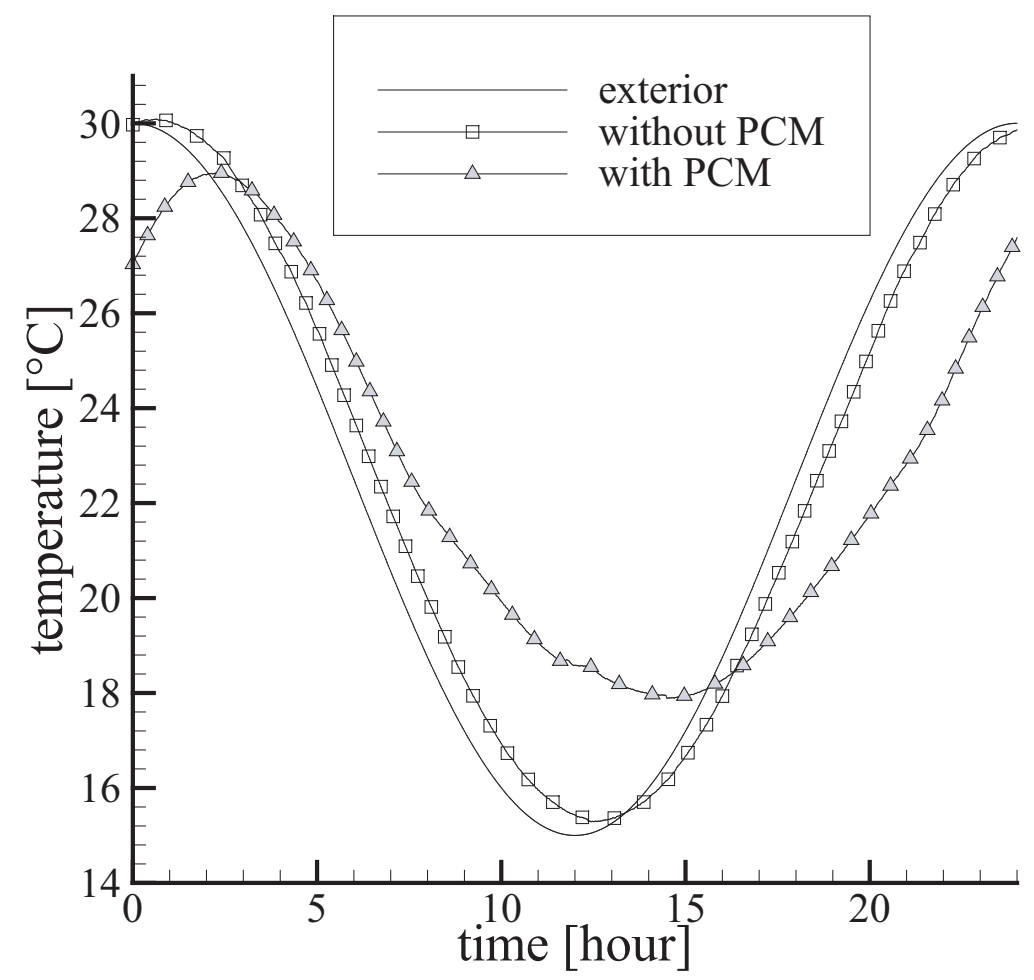

Fig. 12. Temperatures for the boxes with and without PCM - external sinusoidal temperature evolution. 


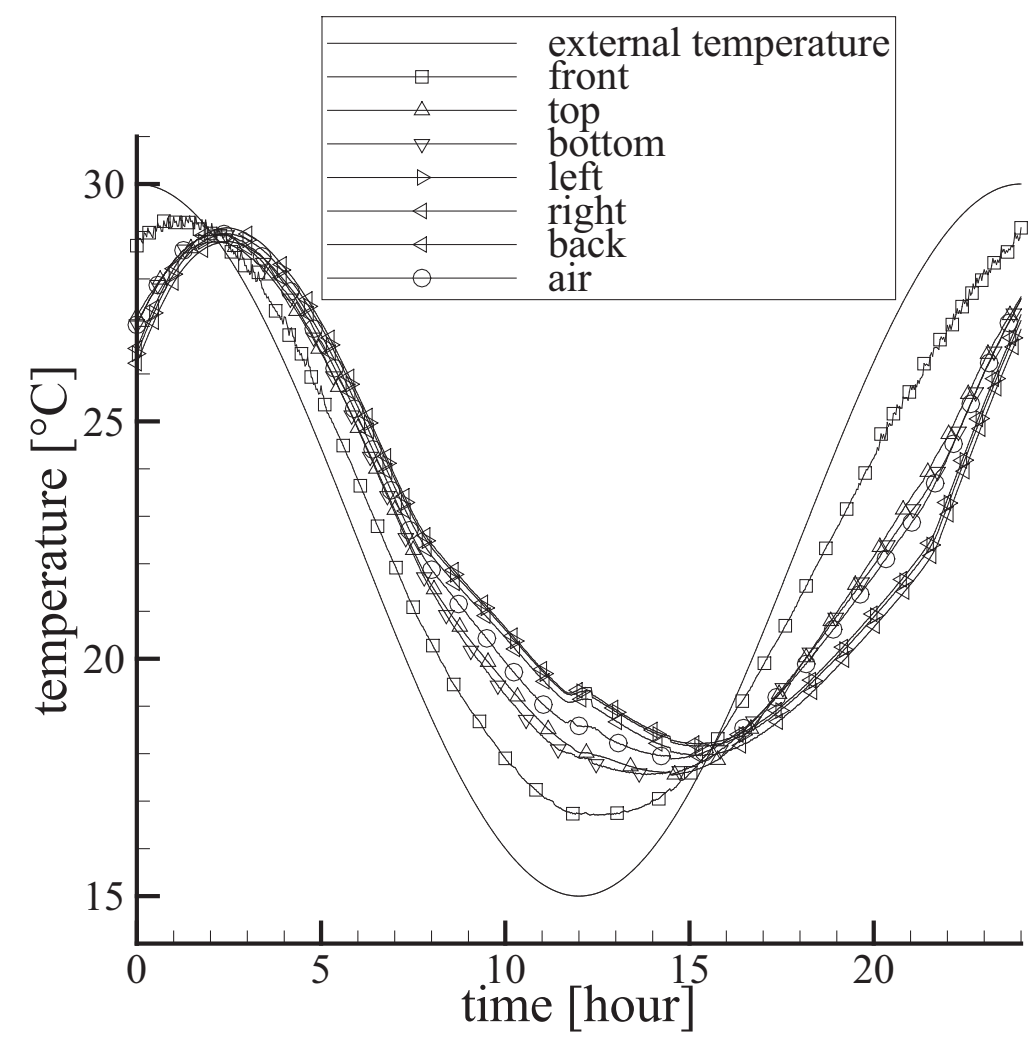

Fig. 13. Temperatures for the boxes with PCM - external sinusoidal temperature evolution. 


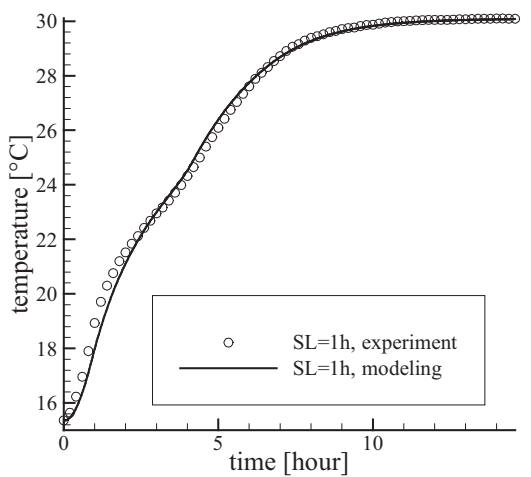

(a)

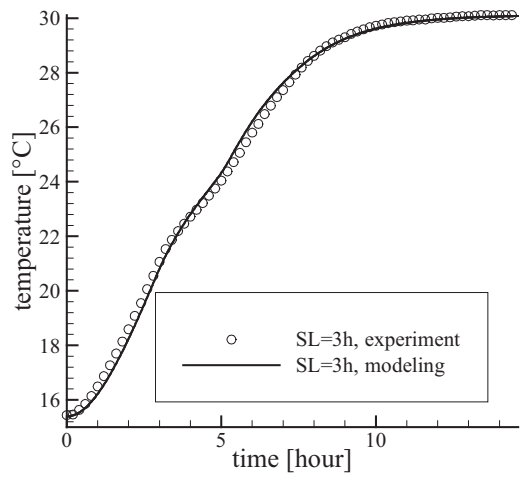

(c)

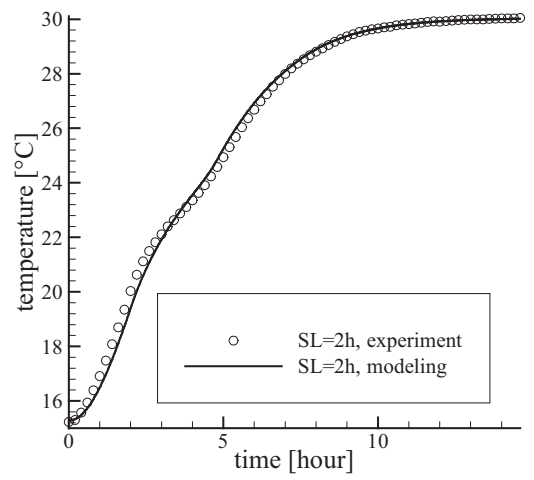

(b)

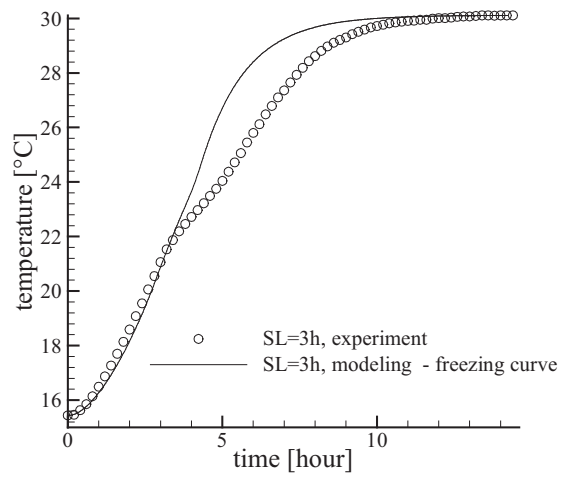

(d)

Fig. 14. Comparison between experimental data and numerical modeling - Heating step. (a), (b) and (c) are modeling using the melting curve of figure 4 whereas (d) uses the freezing curve 


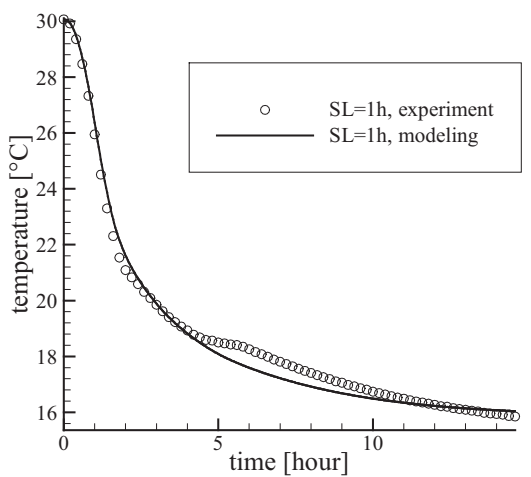

(a)

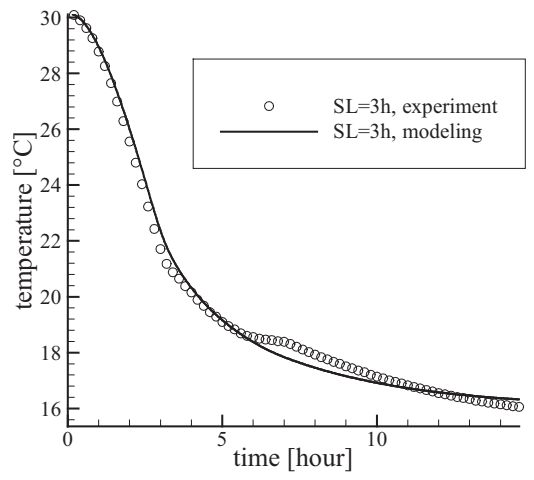

(c)

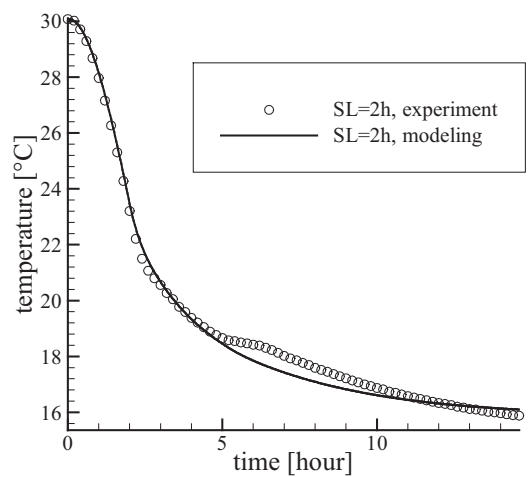

(b)

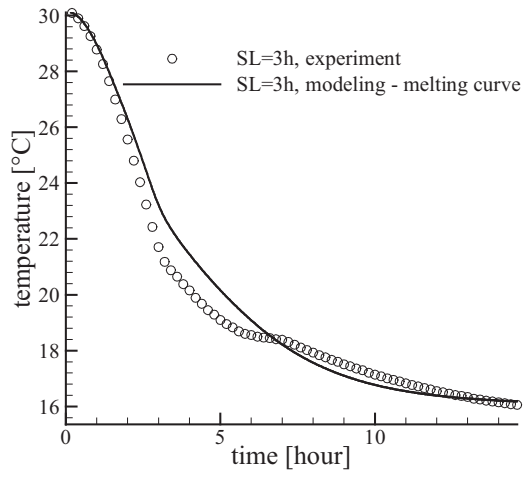

(d)

Fig. 15. Comparison between experimental data and numerical modeling - Cooling step. (a), (b) and (c) are modeling using the freezing curve of figure 4 whereas (d) uses the melting curve 


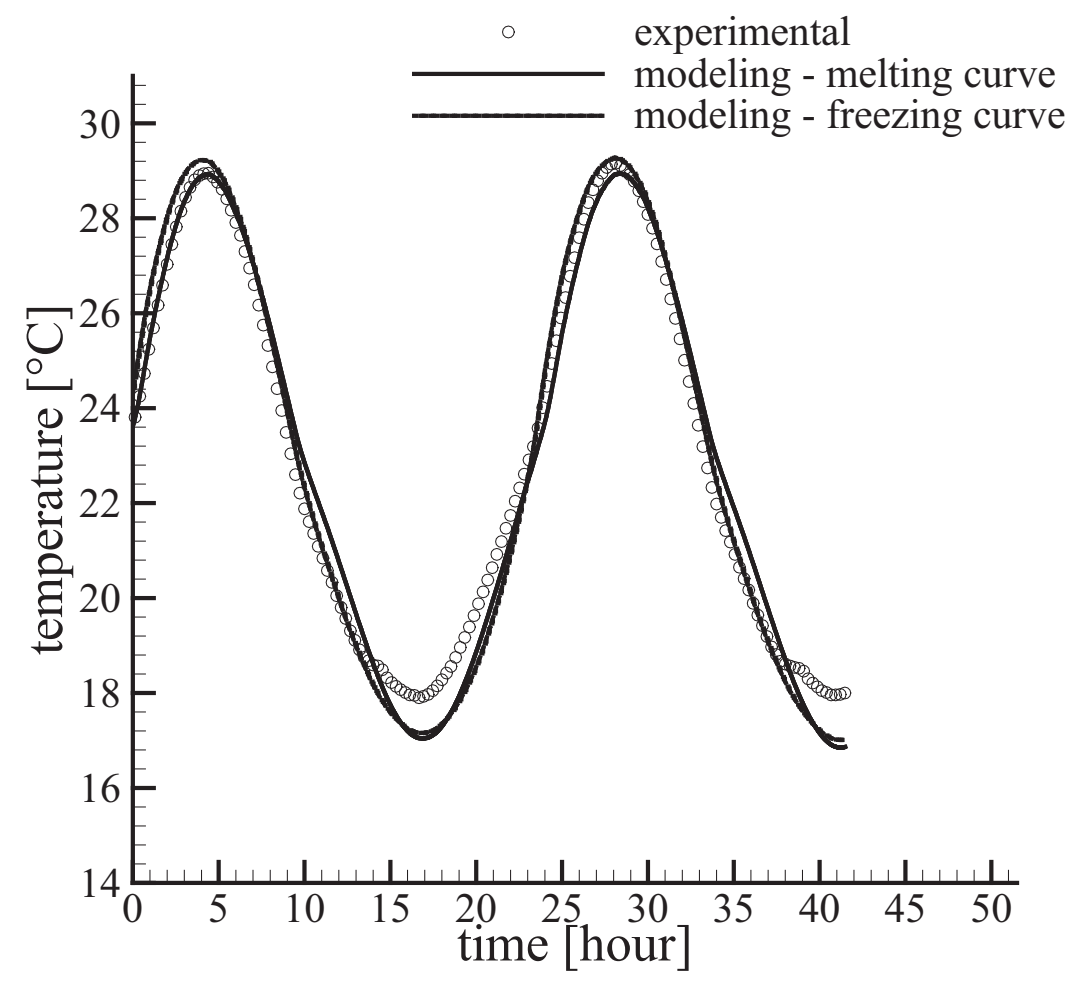

Fig. 16. Comparison between experimental data and numerical modeling - Sinusoidal temperature evolution. 